\title{
MAXIMIZING THE COLLAPSE RESISTANCE OF COMPOSITE STEEL AND CONCRETE STRUCTURES
}

\author{
Georgios S. Papavasileiou ${ }^{1}$ and Dimos C. Charmpis ${ }^{1}$ \\ ${ }^{1}$ Department of Civil and Environmental Engineering, University of Cyprus \\ (papavasileiou.georgios@ucy.ac.cy, charmpis@ucy.ac.cy)
}

\begin{abstract}
The progress of research in combination with the evolution of the available construction technology has allowed the engineers to achieve a more effective use of the material properties, leading this way to the design of more economic, but also more safe structures. At the same time, it enabled the design codes to adjust in order to cover a wider spectrum of dangers, making them stricter in each generation. Various retrofit methods come to add to this lack of capacity of the existing structures; however it is inevitable that the total cost of the existing frame and the retrofit will be higher than the one of a structure designed originally with this capacity.

The present work targets to give a perspective of the correlation between cost and performance of steel and concrete composite frame buildings, providing this way a decision making tool to the engineers who want to achieve the most cost effective design of a structure. For this purpose, the design of 3 composite buildings of different height was optimized for a spectrum of seismic performance levels. The minimization of the total material cost was achieved using the evolution strategies genetic algorithm, which was subject to the following constraints: (a) Eurocode 4 provisions for the composite column-members, (b) Eurocode 3 provisions for the steel beam-members (c) minimum targeted top displacement capacity determined by FEMA 440 and (d) the maximum interstorey drift for the life safety performance level.

The results obtained show the effectiveness of the optimization method used, since there were determined feasible designs with up to 4 times the required capacity. Of particular interest is the comparison of the results obtained for the different building heights in a diagram of normalized cost versus capacity increase coefficient.
\end{abstract}

Keywords: Composite, Steel-Concrete, Optimization, Seismic 


\section{INTRODUCTION}

Optimization algorithms are not a newly developed idea, in order to seek the optimum solution in an area of infinite or just too many feasible ones. However, their application in structural mechanics was delayed due to the increased computational effort required in each iteration. Nowadays, the time of a structural analysis has been significantly reduced thanks to the evolution of personal computers and in combination with the increased need for even more cost-effective and sustainable designs, the total profit of such an application has become attractive again. Composite structures are commonly used because of the reduced labour cost and erection time, as well as the improved architectural results, when designed properly. This work comes to show how the combination of these two can provide an even more competitive solution and investigate its potentials and possible weaknesses.

\section{THE OPTIMIZATION PROBLEM}

The objective function which was minimized in each optimization is the total cost of the materials, which can be simply calculated as:

$$
P_{t o t}=P_{C} \cdot V_{C}+P_{S} \cdot V_{S}
$$

where $P_{t o t}:$ the total cost calculated in local currency

$P_{C}: \quad$ the total cost for the concrete in local currency per $\mathrm{m}^{3}$

$P_{S}: \quad$ the total cost for the steel in local currency per $\mathrm{m}^{3}$

$V_{C}: \quad$ the total volume of concrete $\left(\mathrm{m}^{3}\right)$

$V_{S}: \quad$ the total volume of steel $\left(\mathrm{m}^{3}\right)$

In the aforementioned function, the total cost is calculated in monetary units, which is subject to change at any time, depending on various factors, such as the current prices of the materials, the currency exchange rate, the labour costs etc. If so, whenever one of these factors was altered, the whole problem would also change. In order to avoid such issues, the ratio of concrete cost to steel cost was used in order to convert the total volume of concrete to equivalent steel volume.

$$
V_{t o t}=C R \cdot V_{C}+V_{S}
$$

where $V_{t o t}$ : the total material cost calculated in equivalent steel volume $\left(\mathrm{m}^{3}\right)$

$C R: \quad$ the ratio of the concrete cost to the steel cost $\left(C R=P_{C} / P_{S}\right)$

$V_{C}$ : the total volume of concrete on the storey $\left(\mathrm{m}^{3}\right)$

$V_{S}: \quad$ the total volume of steel on the storey $\left(\mathrm{m}^{3}\right)$

It has to be noted here that the rest of the design parameters such as the total buildings' dimensions and the mechanical properties of the materials both on the column and 
beam section were kept the same during the whole optimization series. The design variables of the problem were the dimensions of the beams' and columns' (in 4 groups) steel sections. Standard IPE sections were used for the beams and HEB sections for the columns, so it becomes obvious that it is a discrete optimization problem.

\section{PERFORMANCE CRITERIA}

\section{Eurocode Provisions}

All the structural elements of the buildings were designed according to the provisions of the Eurocodes. In particular, all the dead and live loads, as well as the wind actions and their combinations were received by EN1990 and EN1991 [2,3], while the checks used for the design of the members, were selected regarding the type of element

\section{Beams \& Bracings - EN1993 [4]}

All the beams of the structures were designed as pure steel beams bearing the loads of the slabs. Using pure steel beams is more preferable in practice, since the construction is easier and the concrete has been found not to have significant contribution to the total section capacity, but mainly offering fire protection to the beams. Moreover, taking into consideration a part of the slab like the common practice in concrete, would automatically mean that the shear connectors between the slab and the beam shall never fail during the whole seismic excitation, since the slabs are not included in the structural model. Although the beams are stressed mostly by the combination of dead and live loads from the slabs, they were checked for all types of actions: bending moment, shear and axial force, as well as the respective buckling types that might occur as a result of these actions. The bracings of the structures are considered to have a hinged connection to the columns on both edges, so they are assumed to be only under axial load.

$$
\begin{aligned}
& M_{R d}=\frac{f_{y k} \cdot W_{e l}}{\gamma_{\mathrm{M} 0}} \\
& V_{R d}=\frac{f_{y k} \cdot A_{V}}{\gamma_{\mathrm{M} 0}} \\
& N_{c, R d}=\frac{f_{y k} \cdot A_{t o t}}{\gamma_{\mathrm{M} 0}}
\end{aligned}
$$

where $M_{R d}, V_{R d}, N_{c, R d}$ : the design bending moment, shear and axial force capacity

$W_{e l}: \quad$ the elastic moment of resistance of the steel section

$A_{V}: \quad$ the effective shear area for each direction 
$A_{\text {tot }}: \quad$ the total area of the section

$f_{y k}$ : the nominal yielding stress of the steel

$\gamma_{M 0}:$ the safety factor used for sections of category 1 to 3

\section{Columns - EN1994 [5]}

The columns were designed only as composite steel-concrete columns, so they are checked according to the provisions of EN1994 for all design actions mentioned for the beams. In addition, the axial shear force criterion for composite columns, which is used in order to determine the number and diameter of the required shear headed stud connectors, was also checked for plenitude reasons, however it is not a criterion that renders a solution unfeasible, as long as the steel section of the column has the required dimensions for the installation of the headed studs. This requirement was found to be satisfied for every feasible solution. Considering the composite operation of the columns ensured, their total capacity can be calculated as the sum of the respective concrete and steel part capacities:

$$
\begin{aligned}
& M_{R d, t o t}=M_{C, R d}+M_{S, R d} \\
& V_{R d, t o t}=V_{C, R d}+V_{S, R d} \\
& N_{R d}=N_{C, R d}+N_{S, R d}
\end{aligned}
$$

\section{FEMA 440 provisions [7]}

As an overall performance criterion of the structure was used the maximum interstorey drift, when the building reaches the target top displacement indicated by FEMA 440. The pushover analysis is considered to give a good estimation of the structural response for buildings up to ten storeys high, with symmetric layout and no significant stiffness and mass variation from storey to storey, so a displacement controlled analysis was used in this work.

$$
\Delta_{t \arg e t}=C_{0} \cdot C_{1} \cdot C_{2} \cdot C_{3} \cdot \frac{S_{a}}{\omega^{2}}
$$

where: $\Delta_{\text {target }}:$ the targeted top displacement to be used in the pushover analysis

$\mathrm{C}_{\mathrm{i}}$ : coefficients used used in order to convert the S.D.O.F. to M.D.O.F. displacement

$\mathrm{S}_{\mathrm{a}}$ : the design pseudo-acceleration defined for a S.D.O.F. system with fundamental period $\mathrm{T}$

$\omega: \quad$ the fundamental frequency of the structure $(=2 \pi / T)$ 


\section{STRUCTURAL SIMULATION}

In total three buildings of the same floor plan, but different height (Figures 1,2) were simulated; a two-storey, a four-storey and a six-storey building of five spans per direction. Each beam's span was $5 \mathrm{~m}$ in both directions and the columns' height was $3.50 \mathrm{~m}$ for all storeys. The effectiveness of grouping the columns instead of using one variable per column is obvious regarding the reduction of computational time. The division of the columns into 4 groups, which had been evaluated in previous works [10] was selected. Group 1 includes all design variables associated with the corner columns. Groups 2 and 3 refer to all side columns in $\mathrm{x}$-direction and y-direction respectively. Group 4 involves all internal columns of the 3D frame. Additionally, all the beams belong to Group 5 and the bracings to Group 6.

All slabs were designed prior to the optimization analyses for both the construction and operation state. However, for the structural simulation, these elements were not included into the model, but their contribution to the total performance was taken into account by distributing their load directly to the beams and defining a rigid diaphragm on each floor level. Beams, columns and bracings were simulated using fibber elements, which are considered to be suitable for this type of analyses, where brittle types of failure are not expected to occur.

In order to take into account the worst case scenario for each structural element, the connection of the beams to the columns was considered to be either hinged, which would result in the maximum bending moment in the beam's span, or fixed, which would transfer the maximum bending moment to the columns.

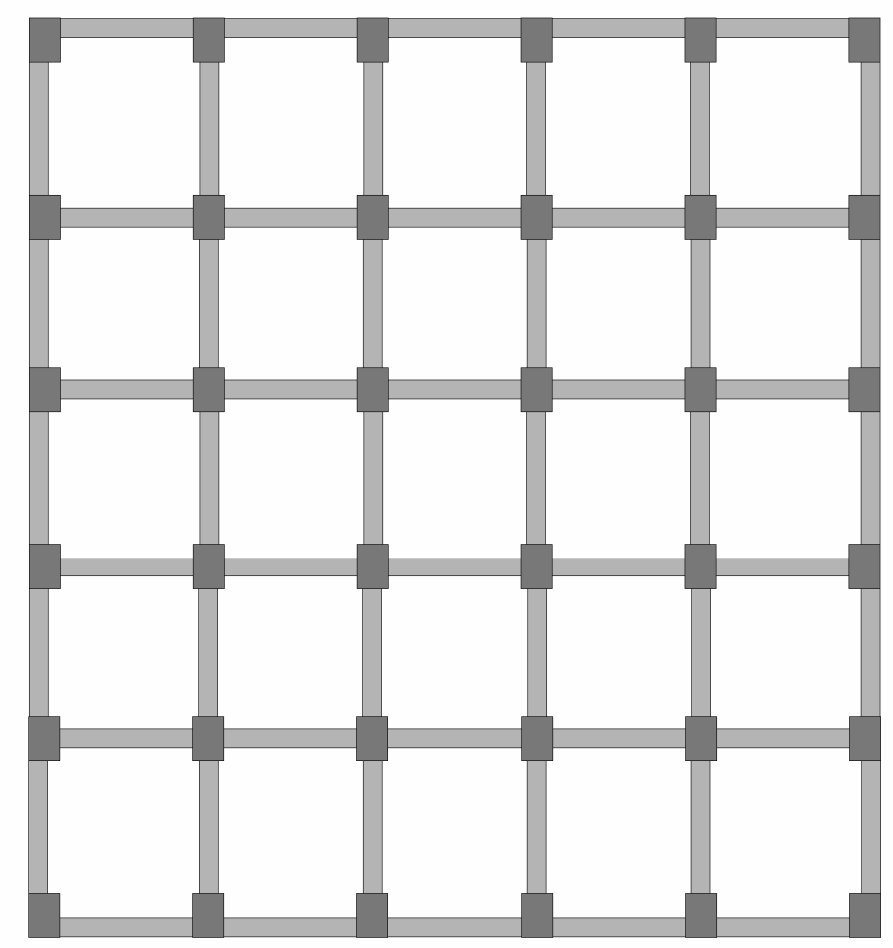

Figure 1. Common floor layout for all buildings 


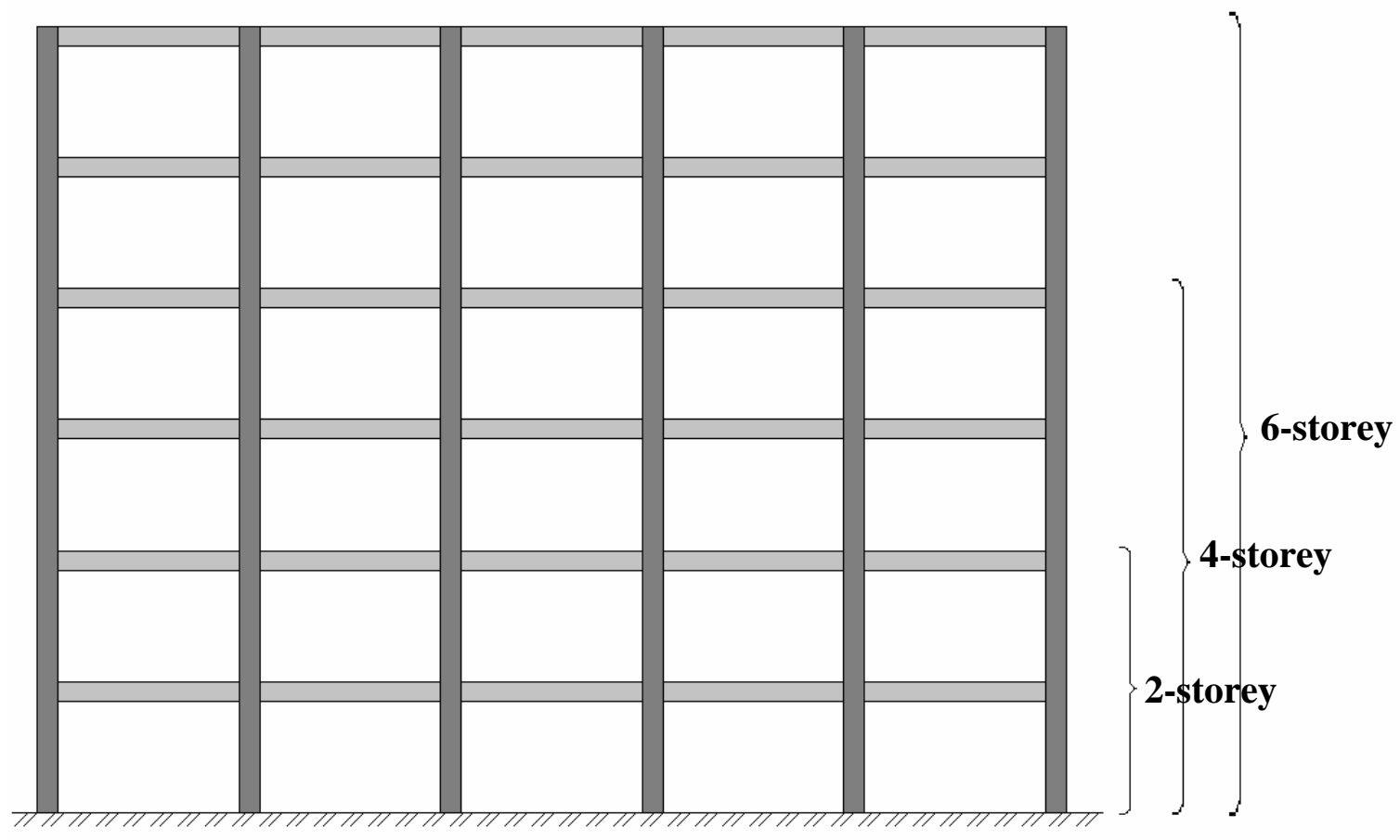

Figure 2. Vertical layout of the three buildings

\section{NUMERICAL RESULTS}

The aim of this work was to determine whether it is feasible or not to design structures with higher capacity, regarding their performance under seismic loads, without excessive increase to their total cost. In order to determine the increment to the total materials cost such a provision would result in, the criterion used was the targeted top displacement, which was multiplied by the coefficient $\delta$ (delta) ranging from 1 to 4 . This way, a design with delta e.g. 2 would have to render the structure able to reach two times the targeted top displacement, without violating the constraints on the structural members' capacity and the total inter-storey drift. The results obtained from the optimizations are presented on Figures 3 to 5. Also, the total cost in terms of percentage of the initial design $(\delta=1)$ is presented in Table 1.

Table 1. Normalized cost per delta level

\begin{tabular}{llll}
\hline \multirow{2}{\delta}{} & \multicolumn{3}{c}{ Normalized Cost (Cost $/$ Cost $_{1}$ ) } \\
\cline { 2 - 4 } & 2-storey & 4-storey & 6-storey \\
$\mathbf{1}$ & $100,00 \%$ & $100,00 \%$ & $100,00 \%$ \\
$\mathbf{2}$ & $100,00 \%$ & $100,00 \%$ & $100,86 \%$ \\
$\mathbf{3}$ & $100,06 \%$ & $102,19 \%$ & $113,35 \%$ \\
$\mathbf{4}$ & $100,19 \%$ & $110,36 \%$ & $155,37 \%$ \\
\hline
\end{tabular}

What is remarkable is that designs which would seem unfeasible otherwise, such as a six-storey building which can reach four times the targeted top displacement, within the desired serviceability limits, became available with much lower increment to the materials 


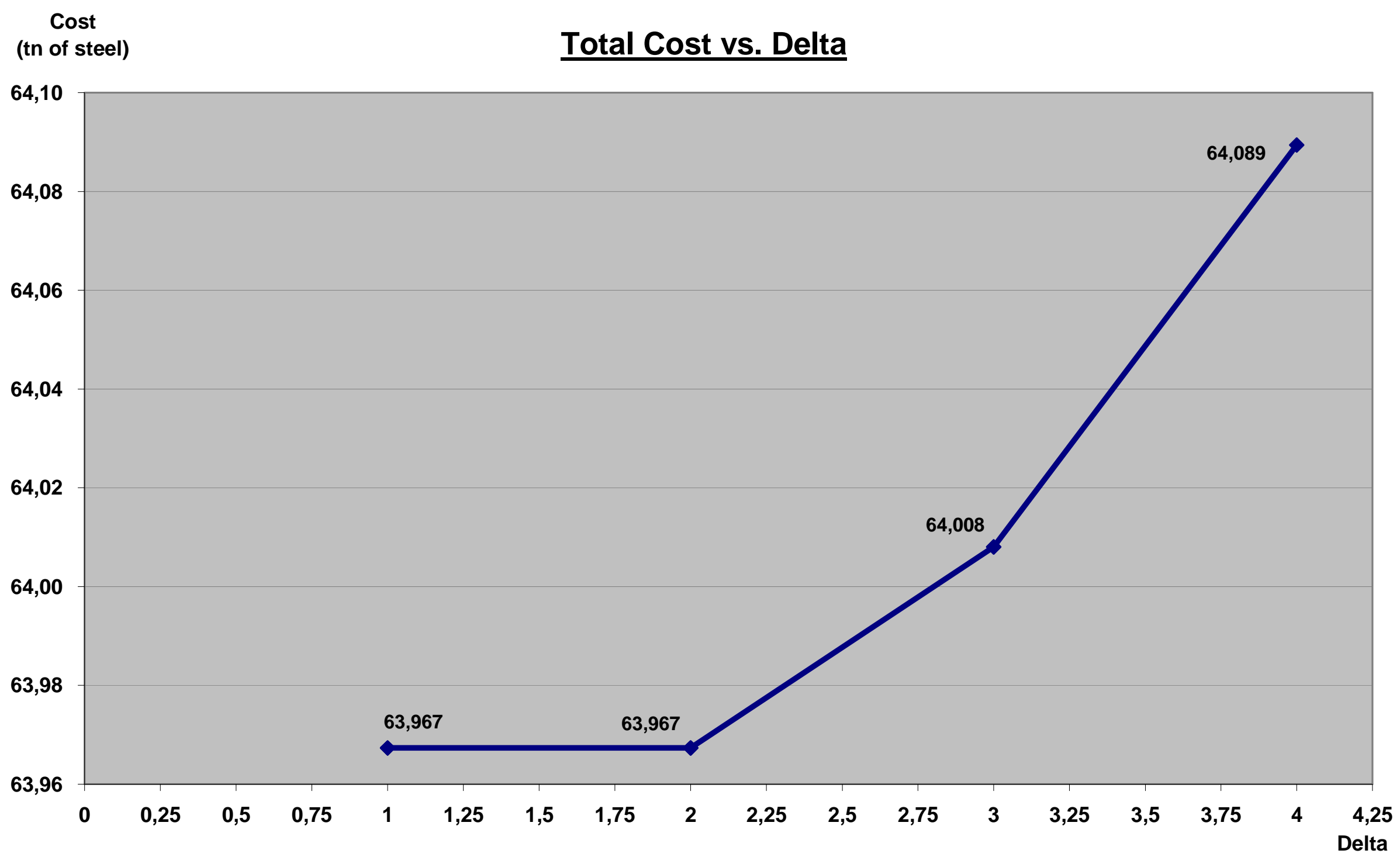

Figure 3. Total cost vs. delta graph for the two-storey building 


\section{Cost}

(tn of steel)

\section{$\underline{\underline{\text { Total Cost vs. Delta }}}$}

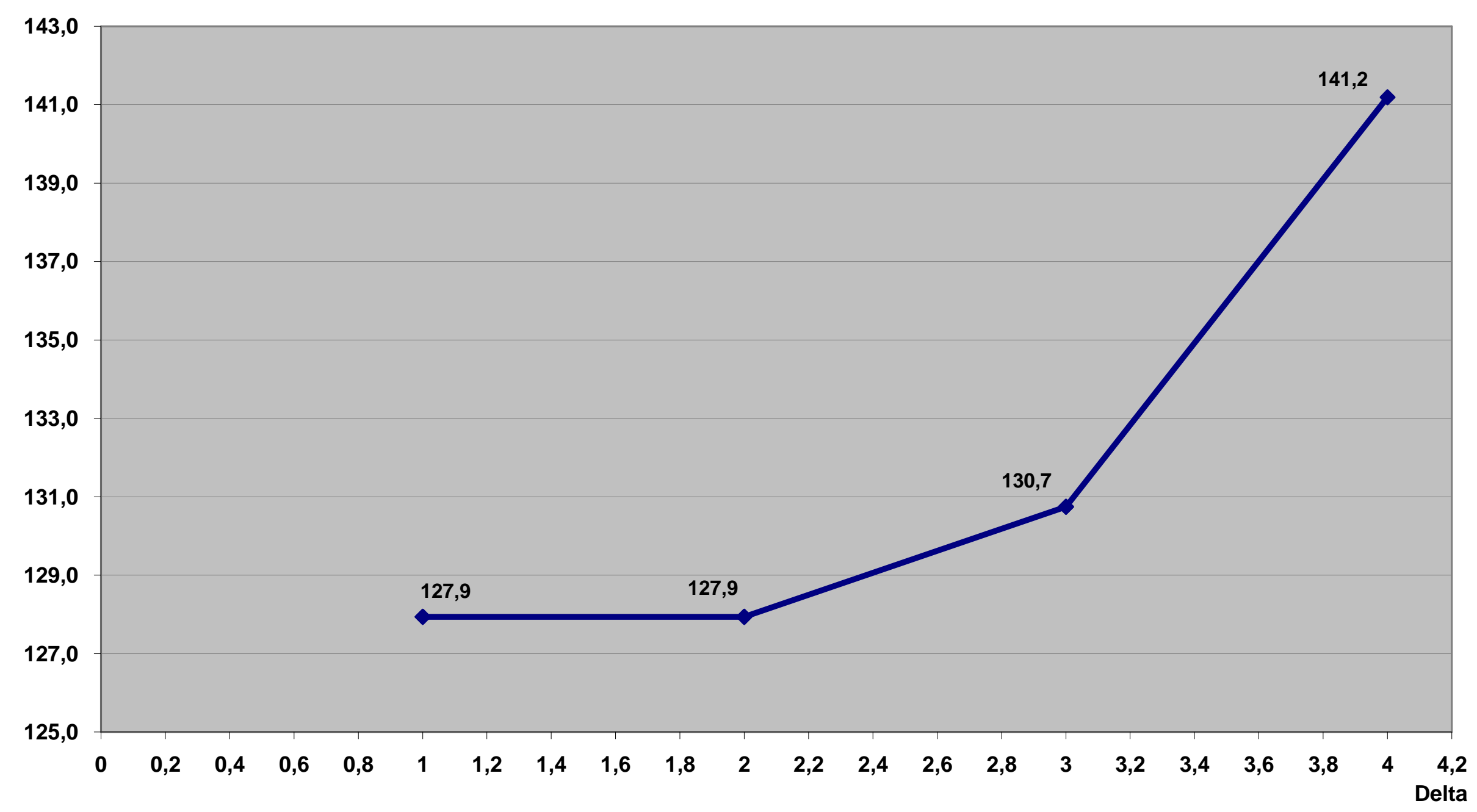

Figure 4. Total cost vs. delta graph for the four-storey building 
Cost

(tn of steel)

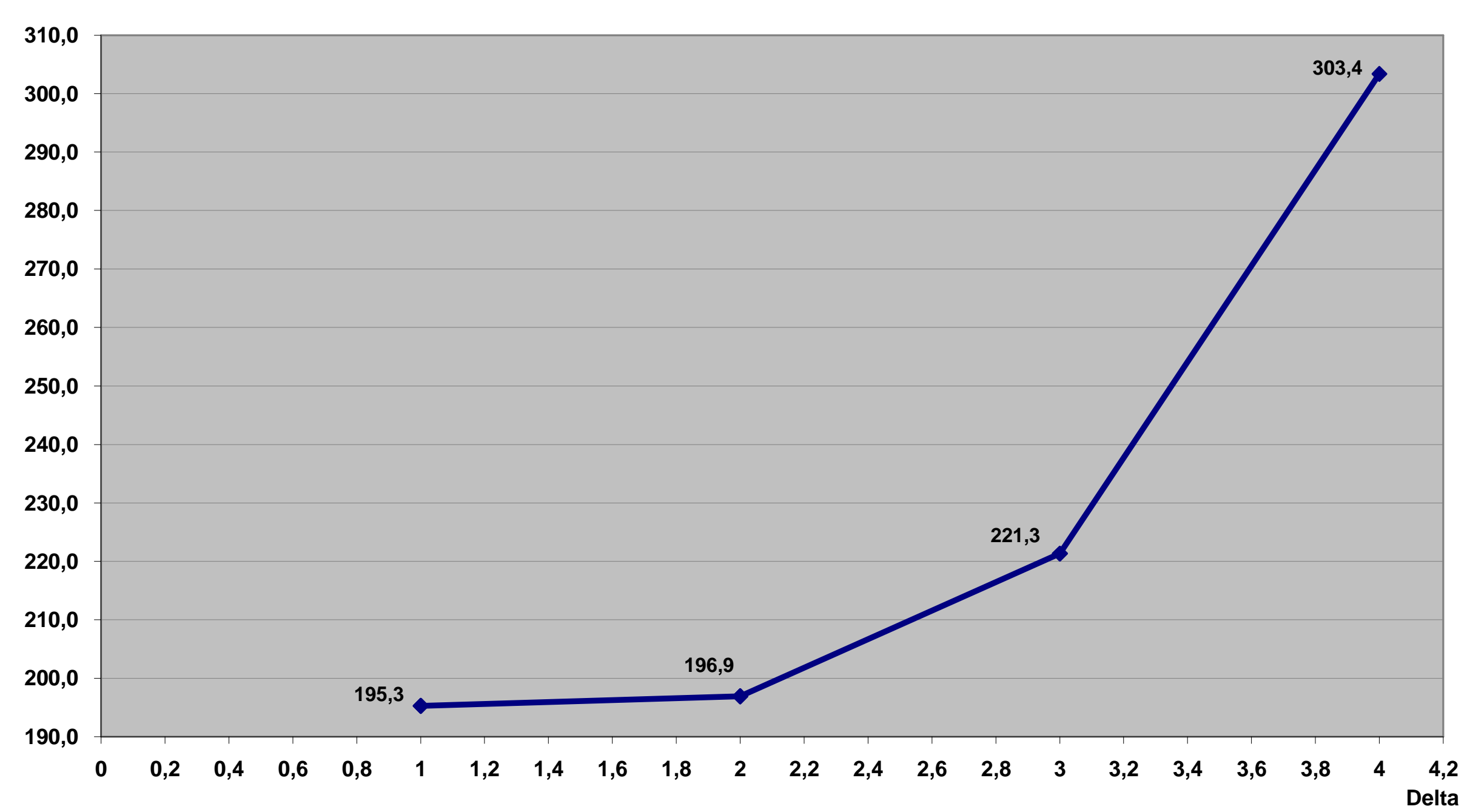

Figure 5. Total cost vs. delta graph for the six-storey building

\section{$\underline{\underline{\text { Total Cost vs. Delta }}}$}




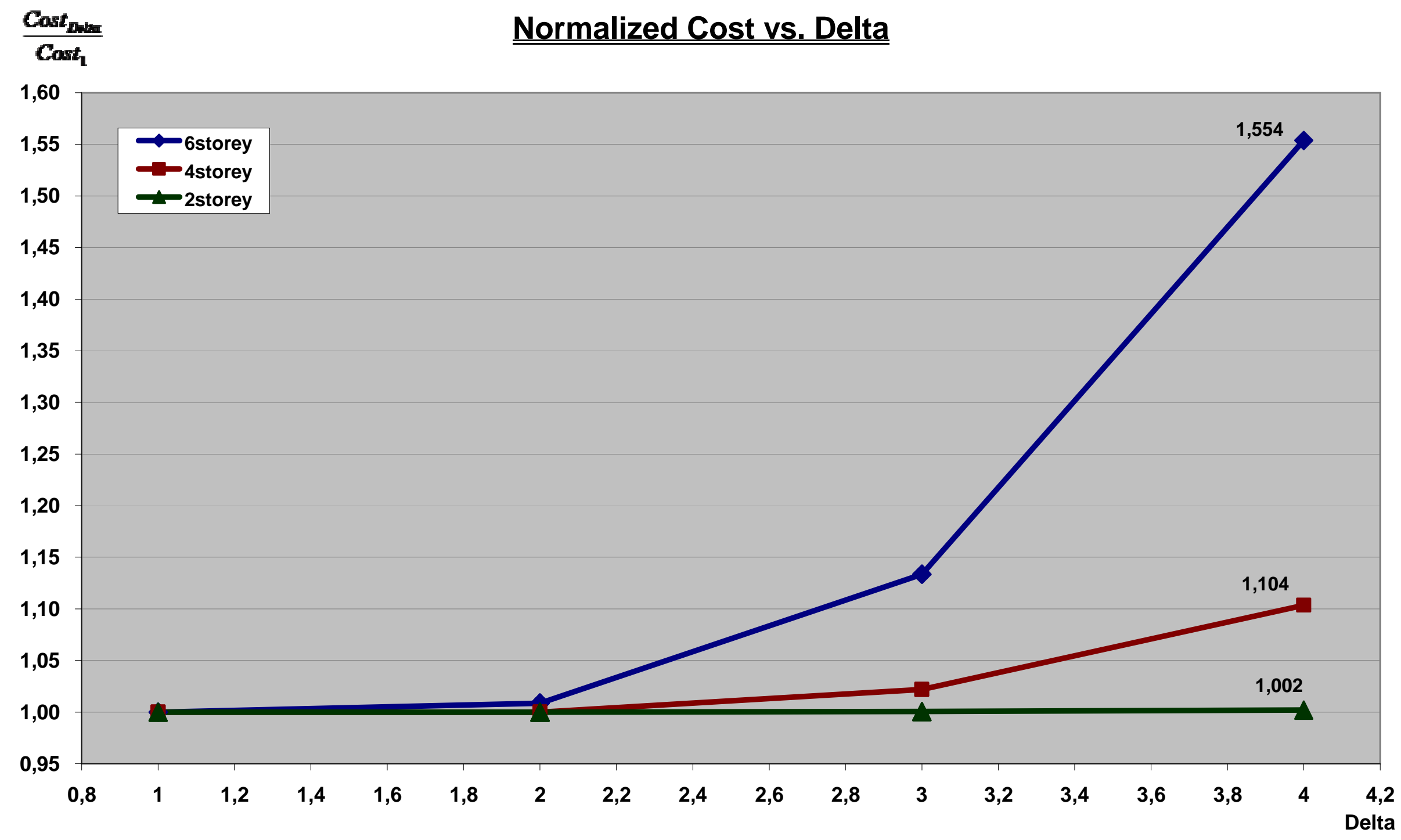

Figure 6. Normalized cost vs. delta graph for all buildings 
cost than it was expected (55.4\% in this case). This shows the efficiency of the optimization method when it is used on high rise buildings, compared to low rise where the increment is ones where a simple parametric study could give similar results. It has to be noted that, during all feasible design scenarios, the usage ratio of the shear capacity of the columns did not exceed $10 \%-12 \%$.

For 1 to 2 times the targeted top displacement, the optimum design seems to be defined by the maximum capacity of the structural elements, since the unfeasible solutions close to the optimum failed to pass the Eurocodes' member checks. This requirement creates an extra displacement capacity to the structure, which explains the horizontal line from delta 1 to 2 ; the optimum design defined for delta 1 can actually reach more than 2 times this displacement and still be within the desired serviceability limits. For higher requirements, the factor which renders a solution close to the optimum design unfeasible is the maximum interstorey drift. It is also noticeable that for higher buildings this extra capacity seems to be reduced, so for such buildings, the optimum solution is a more cost-effective one.

\section{CONCLUSIONS}

The application of optimization algorithms on structural design is a powerful tool which allows engineers to reach the structures beyond their conventional limits, without excessive increase on the total cost. Grouping of columns is found to provide more costeffective designs than using the same section for all columns and keep the required computational time within acceptable limits.

Division of the column sections in more groups (e.g. per storey) would reduce the initial cost even further, but increase significantly the computational time, so, when an engineer decides to use an optimization algorithm, needs to seleect the number of variables which would provide the optimum design, regarding both the reduction of the structural cost and the time needed for the analysis. On the other hand, the same rule does not apply for the beams when the majority of them has similar span (e.g. no more than 10 to $15 \%$ variation on the net span), since their design loads occur mostly by the combination of the dead and live loads of the slabs. So, the beams could easily be designed before the optimization procedure and have this group removed, but the elements still need to be a part of the structural simulation.

Since this was a problem of discrete optimization, the determined designs can reach "at least" and not necessarily "exactly" the defined delta, which is the reason this extra capacity exists. Further study needs to be done in order to determine the maximum delta each of these designs can reach and to shape more precisely the behaviour of the cost vs. delta curves.

Finally, for low rise buildings, the use of an optimization algorithm does not make a significant difference to the total cost, but as the number of storeys increases, the benefits compared to conventional design become more significant. A study of the total benefit versus the time needed as the complexity of the problem increases would allow the engineers to decide whether they should use a parametric analysis, or an optimization procedure/ 


\section{REFERENCES}

[1] Cheng L., Chan C.M., "Optimal lateral stiffness design of composite steel and concrete tall frameworks", Engineering Structures, Elsevier, 2009

[2] Comité Européen de Normalisation (CEN), "Eurocode 0: Basis of structural design", CEN Publications, Brussels, Belgium, 2003

[3] Comité Européen de Normalisation (CEN), "Eurocode 1: Basis of design and actions on structures (ENV 1991)", CEN Publications, Brussels, Belgium, 2003

[4] Comité Européen de Normalisation (CEN), "Eurocode 3: Design of steel structures (ENV 1993)' Part 1-1/1992 General rules and rules for buildings", CEN Publications, Brussels, Belgium, 2003

[5] Comité Européen de Normalisation (CEN), "Eurocode 4: Design of composite structures (ENV 1994)' Part 1-1/1992 General rules and rules for buildings", CEN Publications, Brussels, Belgium, 2003

[6] Comité Européen de Normalisation (CEN), "Eurocode 8: Design provisions for earthquake resistance of structures (ENV 1998)' Part 1-1/1994 General rules - Seismic action and general requirements for structures.", CEN Publications, Brussels, Belgium, 2003

[7] FEMA-440, "Improvement of nonlinear static seismic analysis procedures (FEMA 440)", Federal Emergency Management Agency, Washington D.C., 2005

[8] Fradiadakis M., Lagaros N.D., Papadrakakis M. "Performance based earthquake engineering using structural optimization tools", International Journal of Reliability and Safety, 2006

[9] Fradiadakis M., Papadrakakis M. "Performance based optimum seismic design of reinforced concrete structures", Earthquake Engineering and Structural Dynamics, 2008

[10] Papavasileiou G.S., Charmpis D.C., Lagaros N.D., "Optimized seismic retrofit of steelconcrete composite frames", Proceedings of the $3^{\text {rd }}$ ECCOMAS Thematic Conference on Computational Methods in Structural Dynamics and Earthquake Engineering, 45734586, Corfu, Greece, 2011

[11] Spacone E., El-Tawil S., "Nonlinear Analysis of Steel-Concrete Composite Structures: State of Art", Journal of Structural Engineering, Vol. 130, No. 2, 159-168, A.S.C.E., 2004 